\title{
Clinical Study \\ Perineal Distensibility Using Epi-no in Twin Pregnancies: Comparative Study with Singleton Pregnancies
}

\author{
Juliana Sayuri Kubotani, Antonio Fernandes Moron, Edward Araujo Júnior, \\ Miriam Raquel Diniz Zanetti, Vanessa Cardoso Marques Soares, and Julio Elito Júnior
}

Pelvic Floor Sector, Department of Obstetrics, Federal University of São Paulo (UNIFESP), Rua Carlos Weber, 956 Apartment 113 Visage, Vila Leopoldina, 05303-000 São Paulo, SP, Brazil

Correspondence should be addressed to Edward Araujo Júnior; araujojred@terra.com.br

Received 18 January 2014; Accepted 9 March 2014; Published 27 March 2014

Academic Editors: M. Friedrich and E. Shalev

Copyright (C) 2014 Juliana Sayuri Kubotani et al. This is an open access article distributed under the Creative Commons Attribution License, which permits unrestricted use, distribution, and reproduction in any medium, provided the original work is properly cited.

\begin{abstract}
The aims of this study were to compare perineal distensibility between women with twin and singleton pregnancies and to correlate these women's perineal distensibility with anthropometric data. This prospective cross-sectional case-control study was conducted among nulliparous women, of whom 20 were pregnant with twins and 23 with a single fetus. Perineal distensibility was evaluated in the third trimester by means of Epi-no, which was introduced into the vagina and inflated up to the maximum tolerable limit. It was then withdrawn while inflated and its circumference was measured. The unpaired Student's $t$-test was used to compare perineal distensibility in the two groups and Pearson's correlation coefficient $(r)$ was used to correlate the pregnant women's perineal distensibility with their anthropometric data. There was no difference in perineal distensibility between the twin group (16.51 \pm $2.05 \mathrm{~cm})$ and singleton group $(16.13 \pm 1.67 \mathrm{~cm})(P=0.50)$. There was a positive correlation between perineal distensibility and abdominal circumference $(r=0.36 ; P=0.01)$. The greater the abdominal circumference was, the greater the perineal distensibility was, regardless of whether the pregnancy was twin or singleton.
\end{abstract}

\section{Introduction}

The term pelvic floor refers to all of the muscles, connective tissue, and organs that fill the cavity of the pelvic canal. The muscles of the pelvic floor form a diaphragm that encompasses the pelvic cavity. Their fibers have a U shape around the hiatus, which allows this to be constantly closed, thus providing pelvic support for the abdominal organs [1].

During pregnancy, with uterine growth, the pelvic floor becomes overloaded and, because of the influence of hormones and biomechanical changes to the pelvis, its tonus and strength diminish [2], and urinary symptoms can be observed even before delivery [3].

The Epi-no Delphine Plusvaginal dilator (Starnberg Medical, Tecsana GmbH, Munich, Germany) consists of an inflatable silicone balloon connected to a manometer via a rubber tube $[4,5]$. In the absence of any instrument that could quantify this stretching, the Epi-no apparatus was adapted to objectively and quantitatively evaluate the degree of perineal distensibility.
In twin pregnancies, the gestational changes are more pronounced, given that there are two fetuses, two placentas, and amniotic fluid for two fetuses, thus producing an even greater overload on the pelvic floor. From this supposition, the purposes of the present study were to compare the degree of distensibility of the musculature of the pelvic floor among women with twin pregnancies with that of women with singleton pregnancies, by means of the Epi-no vaginal dilator, and to correlate these pregnant women's perineal distensibility with their anthropometric data.

\section{Materials and Methods}

A prospective cross-sectional case-control study was conducted between August 2011 and April 2013. For this, 20 women with twin pregnancies and 23 with singleton pregnancies aged between 20 and 38 years, all nulliparous, were selected. The pregnant women came from the outpatient clinics of the Department of Obstetrics, Federal University 
of São Paulo (UNIFESP), at gestational ages of between 20 and 38 weeks. This study was approved by the Research Ethics Committee of UNIFESP under the number 0506/11, and all the pregnant women signed a free and informed consent statement.

Pregnant women who presented the following dysfunctions of the pelvic floor were excluded: urinary or fecal incontinence or genital prolapse prior to pregnancy; fetal abnormalities detected in ultrasonography examinations; previous fetal death at a gestational age of more than 20 weeks; monochorionic twin pregnancies complicated by twin-totwin transfusion syndrome, acardiac fetus or conjoined twins; or multiple pregnancies with three or more fetuses.

To evaluate perineal distensibility, the pregnant women were positioned in dorsal decubitus with their lower limbs flexed and abducted at between $30^{\circ}$ and $45^{\circ}$ and with their feet supported on the bed. The woman was instructed not to perform contraction of the perineal, gluteal, or adductor musculature or to perform a Valsalva maneuver. The Epino balloon was introduced into the vagina in a deflated condition, enclosed in a gel-lubricated condom, to a depth that would allow $2.0 \mathrm{~cm}$ of the balloon to be viewed outside of the vagina [6]. In this way, no risk would be presented to the pregnant woman because the device would not reach the uterine neck. The Epi-no balloon was then gradually inflated until the pregnant woman signaled that she perceived or felt that the distension had reached its maximum tolerable limit. The balloon was then withdrawn without deflating it, delicately, such that the woman would not apply force to resist or assist the withdrawal, and the circumference of the balloon was measured using a measuring tape.

To determine the number of subjects needed to this study, we used Cochran's formula $n=t^{2} \times P x(1-P) / d^{2}$ [7]. Considering a normal distribution to " $P$," we can adopt $t=1.96$, which means that the area under the normal curve will have size 0.05 ; furthermore, we will adopt a margin of error of $5.0 \%$. " $P$ " was fixed in $1 \%(0.01)$ and therefore $(1-P)$ has value of 0.99 . Thus, with a margin of error of $5.0 \%$, we would need minimum of 16 subjects to each group.

The data were transferred to a spreadsheet in the Excel 2007 software (Microsoft Corp., Redmond, WA, USA) and were analyzed using the Statistical Package for the Social Sciences (SPSS) software for Windows, version 15.0 (SPSS Inc., Chicago, IL, USA). To compare the data obtained from analysis on the Epi-no circumference measurements, between the two study groups, the unpaired Student's $t$-test was used. To correlate perineal distensibility with the pregnant women's anthropometric data, Pearson's correlation coefficient $(r)$ was used. The significance level of $P<0.05$ was used in all of the analyses.

\section{Results}

The mean maternal age in the group of women with singleton pregnancies $(n=23)$ was $29.82 \pm 6.10$ years, while in the group with twin pregnancies $(n=20)$ it was $26 \pm 4.35$ years $(P=0.03)$. The mean gestational age at the time of the evaluation in the group with singleton pregnancies

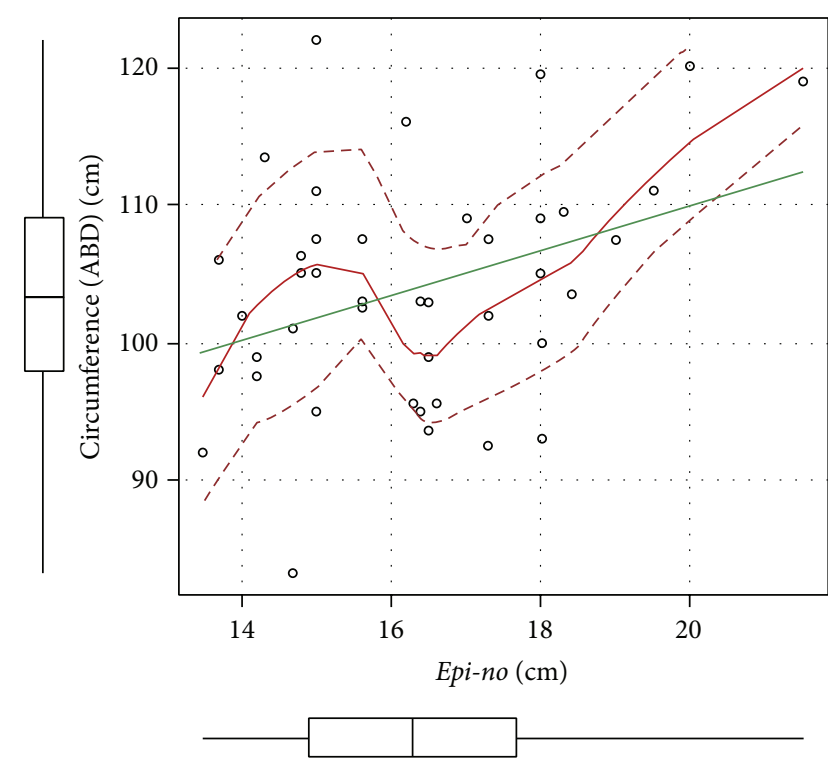

FIGURE 1: Graphical representation of the positive correlation between abdominal circumference (ABD) and measurements on the Epi-no balloon circumference.

was $32.68 \pm 2.30$ weeks, while in the group with twin pregnancies, it was $31.77 \pm 1.42$ weeks $(P=0.12)$. The mean uterine height and abdominal circumference were $30.36 \pm$ $2.34 \mathrm{~cm}$ and $99.67 \pm 6.84 \mathrm{~cm}$, respectively, in the pregnant women with singletons, while among the women with twin pregnancies these were $35.15 \pm 2.58 \mathrm{~cm}$ and $108.64 \pm 7.61 \mathrm{~cm}$, respectively, with $P<0.01$. Regarding the gestational body mass index (BMI), the women with singletons had a mean of $26.31 \pm 3.46 \mathrm{~kg} / \mathrm{cm}^{2}$ and those with twins presented $29.51 \pm$ $4.94 \mathrm{~kg} / \mathrm{cm}^{2}(P=0.01)$ (Table 1$)$.

The mean circumference of the Epi-no balloon among all the pregnant women was $16.31 \pm 1.85 \mathrm{~cm}$. In the group with twins, it was $16.51 \pm 2.05 \mathrm{~cm}$, while, in the group with singletons, it was $16.13 \pm 1.67 \mathrm{~cm}(P=0.50)$ (Table 2).

There was a positive and statistically significant correlation between abdominal circumference and the circumference of the Epi-no balloon $(r=0.36 ; P=0.01)$ and a trend in the correlation between BMI and Epi-no (Table 3 and Figure 1).

\section{Discussion}

Pregnancy causes biomechanical, neurological, and neuromuscular modifications to the pelvic floor through mechanical and hormonal effects [8]. Examples of mechanical effects include increased weight, overload generated through the fetal weight, and postural changes, while the hormonal effects come mainly from the action of progesterone and relaxin. The latter is responsible for greater joint flexibility, thus leading to the increased pelvic mobility that is evident from the start of the third gestational trimester $[9,10]$.

In twin pregnancies, the characteristics of both the overload on the pelvic floor and the hormonal changes are presented more intensely than in singleton pregnancies. Some 
TABLE 1: Patient distribution according to demographic and anthropometric characteristics.

\begin{tabular}{|c|c|c|c|c|c|}
\hline Variable & Group & $N$ & Mean & Standard deviation & Significance $(P)$ \\
\hline \multirow{2}{*}{ Age } & singleton & 23 & 29.82 & 6.10 & \multirow{2}{*}{$0.03^{*}$} \\
\hline & twin & 20 & 26 & 4.35 & \\
\hline \multirow{2}{*}{ GA } & singleton & 23 & 32.68 & 2.30 & \multirow{2}{*}{$0.12^{* *}$} \\
\hline & twin & 20 & 31.77 & 1.42 & \\
\hline \multirow{2}{*}{$\mathrm{UH}$} & singleton & 22 & 30.36 & 2.34 & \multirow{2}{*}{$<0.01^{* *}$} \\
\hline & twin & 20 & 35.15 & 2.58 & \\
\hline \multirow{2}{*}{$\mathrm{AC}$} & singleton & 22 & 99.67 & 6.84 & \multirow{2}{*}{$<0.01^{* *}$} \\
\hline & twin & 19 & 108.64 & 7.61 & \\
\hline \multirow{2}{*}{ BMI } & singleton & 22 & 26.31 & 3.46 & \multirow{2}{*}{$0.01^{* *}$} \\
\hline & twin & 20 & 29.51 & 4.94 & \\
\hline
\end{tabular}

GA: gestational age; UH: uterine height; AC: abdominal circumference; BMI: body mass index.

${ }^{*}$ Mann Whitney.

${ }^{* *}$ Unpaired Student's $t$-test.

TABLE 2: Comparison of data from measurements on Epi-no balloon circumference between the twin and singleton pregnancy groups.

\begin{tabular}{lcccccr}
\hline Epi-no balloon circumference & $n$ & Minimum & Maximum & Mean & Standard deviation & $P^{*}$ \\
\hline Twin pregnancy & 20 & 14 & 21.5 & 16.51 & 2.05 & 0.50 \\
Singleton pregnancy & 23 & 13.5 & 19.5 & 16.13 & 1.67 & \\
\hline
\end{tabular}

${ }^{*}$ Unpaired Student's $t$-test.

TABLE 3: Correlation between the pregnant women's anthropometric data and their measurements from the Epi-no balloon circumference.

\begin{tabular}{lccc}
\hline Pair of variables & $r$ & $P$ & Interval \\
\hline MA versus Epi-no & -0.07 & 0.62 & {$[-0.36,0.22]$} \\
GA versus Epi-no & 0.03 & 0.84 & {$[-0.27,0.32]$} \\
UH versus Epi-no & 0.20 & 0.19 & {$[-0.10,0.48]$} \\
BMI versus Epi-no & 0.28 & 0.06 & {$[-0.02,0.54]$} \\
AC versus Epi-no & 0.36 & $0.01^{*}$ & {$[0.06,0.59]$} \\
\hline
\end{tabular}

MA: maternal age; GA: gestational age; UH: uterine height; AC: abdominal circumference; BMI: body mass index; $r$ : Pearson's correlation coefficient.

${ }^{*}$ Unpaired Student's $t$-test.

authors have correlated twin pregnancies and delivery type with conditions of stress urinary incontinence, urge urinary incontinence, fecal incontinence, and gas incontinence using questionnaires alone [11-13], without any type of physical evaluation of the pelvic floor or any comparison with women with single pregnancies.

With the aim of reducing occurrences of perineal laceration and the need for expansion incisions at the time of delivery, the Epi-no device was developed. Its original purpose was to assist in preparing the perineum so that episiotomy might be avoided [5]. In the present study, we adapted the Epi-no balloon in order to evaluate the degree of perineal distensibility: to the best of knowledge, no studies on this have yet been published in the literature, in relation to either single or twin pregnancies.

There are some difficulties relating to evaluations on perineal distensibility. Among these is the patients' fear that the examination might trigger delivery labor, even after explanation that the Epi-no balloon does not reach the uterine neck, and despite the fact that no study in the literature has ever demonstrated that Epi-no would be able to stimulate delivery labor. Psychological issues, especially among women with twin pregnancies, who are always advised by the medical team regarding the risks of prematurity, may have an influence on the examination, given that this examination has a direct relationship with the patient's discomfort, through indication of the insufflation limit of the Epi-no balloon.

From a more detailed analysis in which we grouped the women with twin and singleton pregnancies, we observed that the greater the abdominal circumference was, the greater the circumference of the Epi-no balloon was. Moreover, there was a tendency for the distensibility of the pelvic floor to be greater with greater BMI, with the observation that there was greater overload on the pelvic floor through increased continual pressure on this.

\section{Conclusion}

In summary, we did not observe any significant differences between the twin and singleton pregnancy groups with regard to perineal distensibility, as assessed using the Epi-no balloon. On the other hand, we observed a positive correlation between perineal distensibility and the mother's abdominal circumference.

\section{Conflict of Interests}

The authors declare that there is no conflict of interests regarding the publication of the paper. 


\section{References}

[1] J. A. Ashton-Miller and J. O. L. DeLancey, "On the biomechanics of vaginal birth and common sequelae," Annual Review of Biomedical Engineering, vol. 11, pp. 163-176, 2009.

[2] M. R. Zanetti and C. D. Petricelli, "Fisioterapia obstétrica: considerações terapêuticas e exercícios físicos," in Obstetrícia, A. F. Moron, L. Camano, and L. Kulay Jr, Eds., p. 155, Manole, Barueri, Brazil, 1st edition, 2011.

[3] J. Wijma, A. E. Weis Potters, B. T. H. M. De Wolf, D. J. Tinga, and J. G. Aarnoudse, "Anatomical and functional changes in the lower urinary tract following spontaneous vaginal delivery," An International Journal of Obstetrics and Gynaecology, vol. 110, no. 7, pp. 658-663, 2003.

[4] J. Hillebrenner, S. Wagenpfeil, R. Schuchardt, M. Schelling, and K. T. Schneider, "Initial experiences with primiparous women using a new king of Epi-no labor trainer," in Zeitschrift für Geburtshilfe und Neonatologie, vol. 205, pp. 12-19, 2001.

[5] G. T. Kovacs, P. Heath, and C. Heather, "First Australian trial of the birth-training device Epi-no: a highly significant increased chance of an intact perineum," Australian and New Zealand Journal of Obstetrics and Gynaecology, vol. 44, no. 4, pp. 347348, 2004.

[6] J. Kok, K. H. Tan, S. Koh et al., "Antenatal use of a novel vaginal birth training device by term primiparous women in Singapore," Singapore Medical Journal, vol. 45, no. 7, pp. 318-323, 2004.

[7] W. Cochran, Sampling Techniques, John Wiley \& Sons, Boston, Mass, USA, 2nd edition, 1985.

[8] K. L. Shek, J. Kruger, and H. P. Dietz, "The effect of pregnancy on hiatal dimensions and urethral mobility: an observational study," International Urogynecology Journal, vol. 23, pp. 15611567, 2012.

[9] M. Polden and J. Mantle, Fisioterapia em Ginecologia e Obstetrícia, Santos, São Paulo, Brazil, 2000.

[10] E. Baracho, Fisioterapia Aplicada à Obstetrícia, Urogin Ecologia e Aspectos de Mastologia, Guanabara Koogan, Rio de Janeiro, Brazil, 4th edition, 2007.

[11] R. P. Goldberg, C. Kwon, S. Gandhi et al., "Urinary incontinence among mothers of multiples: the protective effect of cesarean delivery," American Journal of Obstetrics and Gynecology, vol. 188, no. 6, pp. 1447-1453, 2003.

[12] G. Legendre, J. Tassel, L.-J. Salomon, A. Fauconnier, and G. Bader, "Impact of twin gestation on the risk of postpartum stress incontinence," Gynecologie Obstetrique Fertilite, vol. 38, no. 4, pp. 238-243, 2010.

[13] M. J. Cuerva González, N. López Carpintero, M. M. de la Calle Fernández, R. Usandizaga, and A. González, "Postpartum urinary and fecal incontinence in gemelar pregnancy according to route and mode of delivery," Ginecología y Obstetricia de México, vol. 79, pp. 540-546, 2011. 


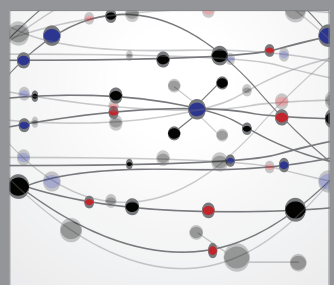

The Scientific World Journal
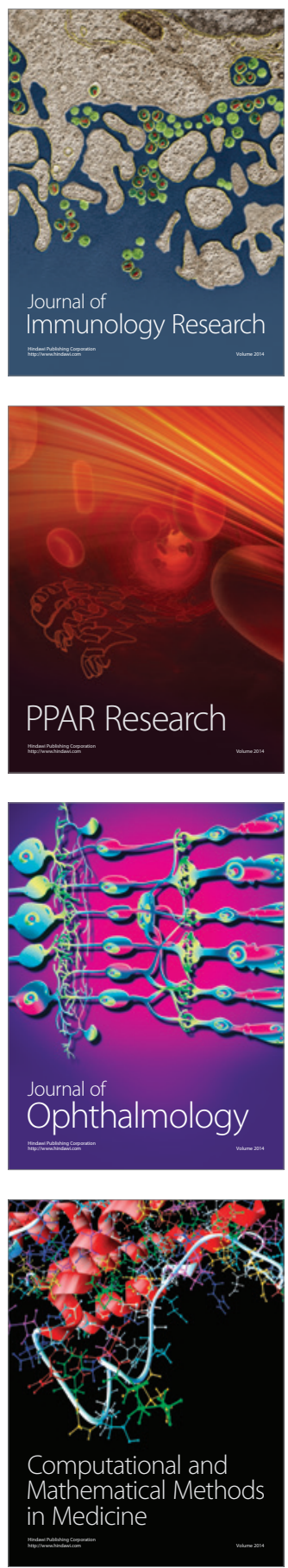

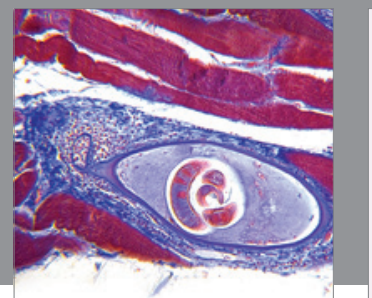

Gastroenterology

Research and Practice
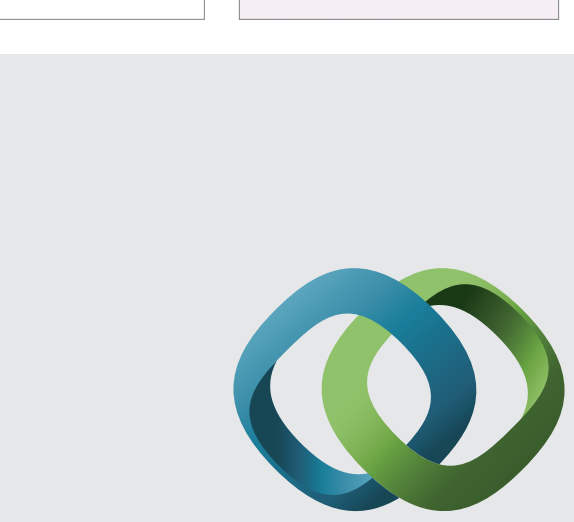

\section{Hindawi}

Submit your manuscripts at

http://www.hindawi.com
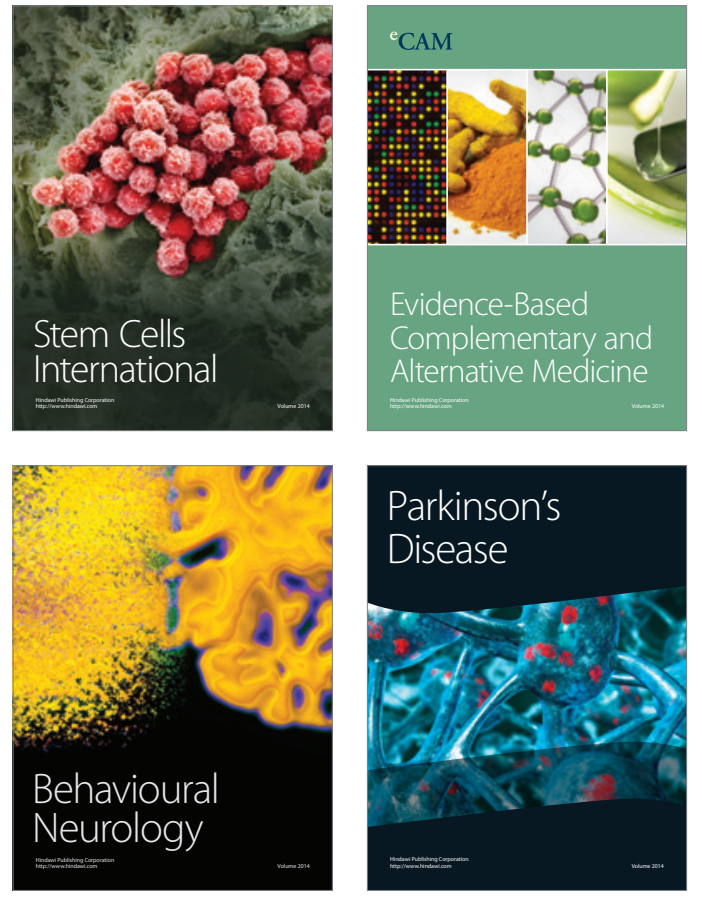
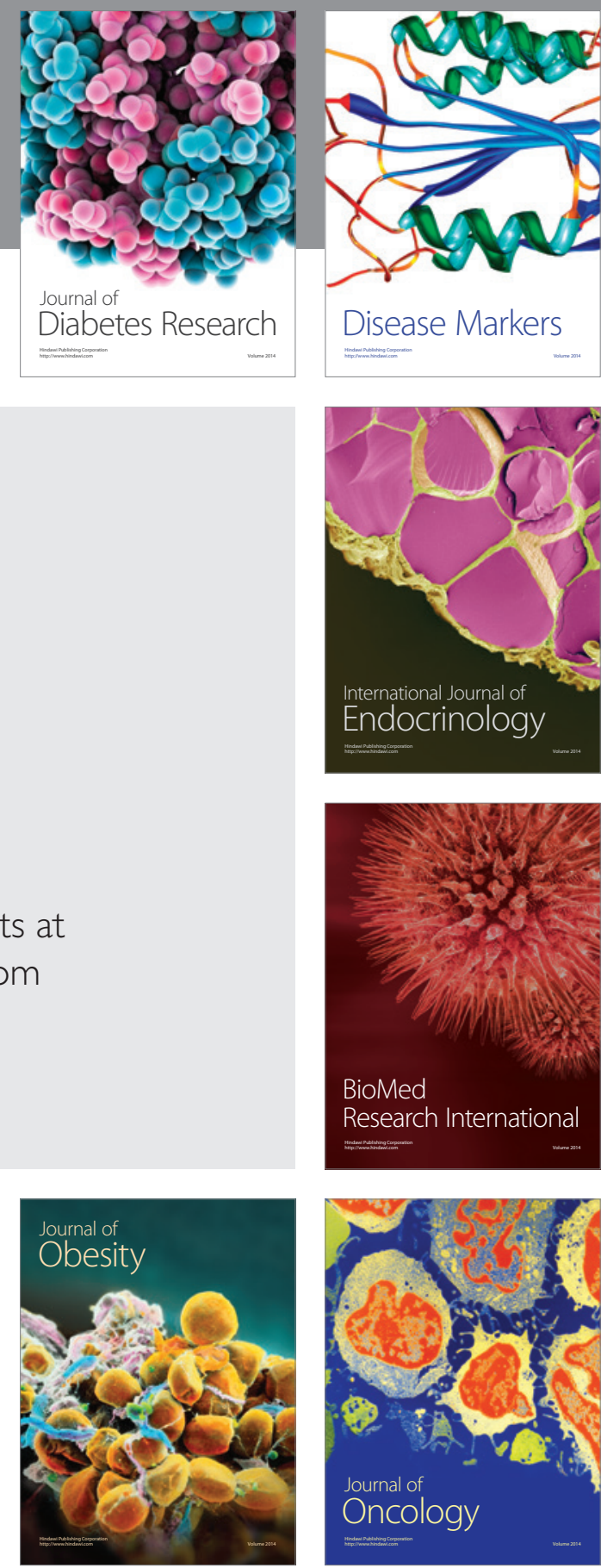

Disease Markers
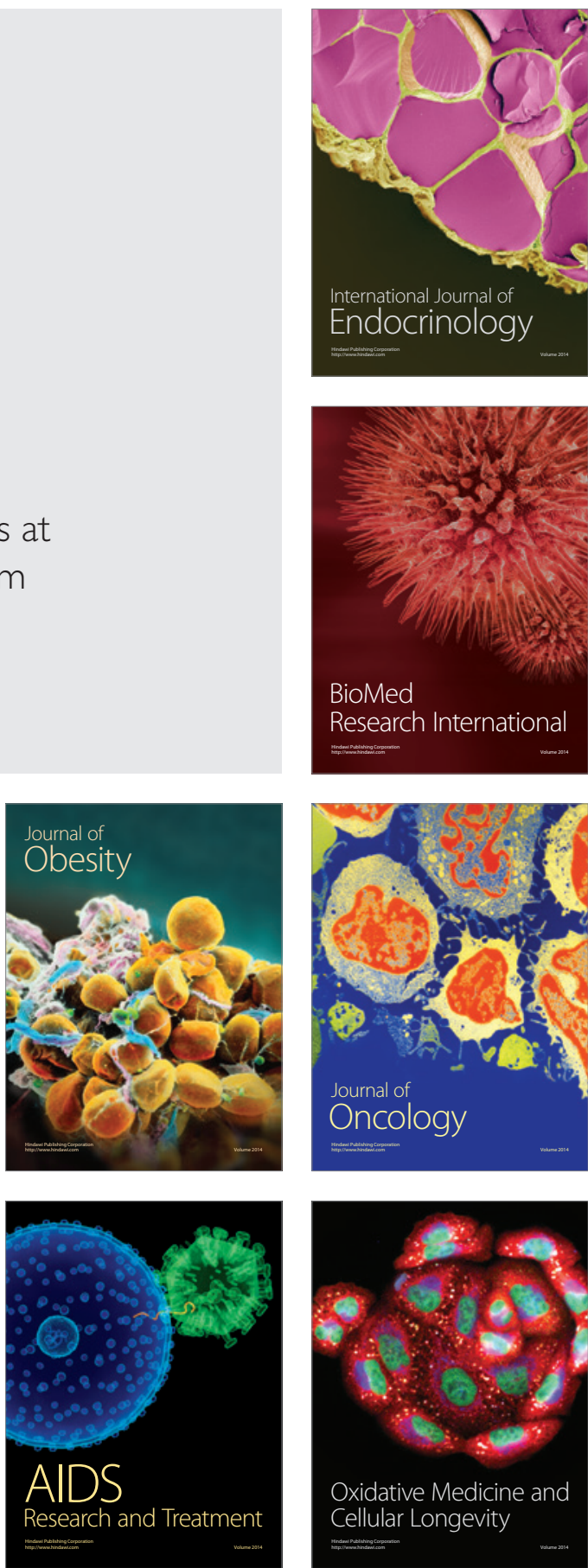